\title{
A justiça constitucional estadual e os direitos fundamentais eleitorais: $o$ caso Jalisco'
}

\section{Luis Antonio Corona Nakamura}

\section{Resumo}

O ser humano tem, de forma inata, uma dignidade reconhecida desde o direito natural. Assim, o homem per se possui direitos considerados fundamentais, ao ponto de restarem reconhecidos nos instrumentos internacionais e regulados nas Constituições, com o intuito de reforçar a ideia da dignidade de todas as pessoas, bem como dos princípios que fazem referência à liberdade, dignidade e igualdade. Os direitos humanos e os direitos fundamentais, embora guardem uma relação estreita entre sim, não são sinônimos, sendo um dos propósitos do presente trabalho a sua necessária definição. Os direitos civis e políticos - como, por exemplo, o voto ativo, o voto passivo e a livre afiliação e associação aos mais diversos pensamentos políticos - são direitos humanos e fundamentais reconhecidos em nossa Carta Magna e instrumentos internacionais, pelo que o Estado Mexicano deve resguarda-los e garantir sua proteção. Não obstante, também nas entidades federativas do México, entre elas o Estado de Jalisco, deve-se contar com os mecanismos de controle constitucional e convencional para proteger os direitos humanos fundamentais eleitorais e é neste ponto que surge a necessidade de analisar se o sistema de justiça constitucional estadual efetivamente cumpre com a obrigação de sua proteção.

Palavras-chave: Direitos fundamentais humanos; voto ativo; voto passivo; proteção, tutela.

\begin{abstract}
Human beings have, innately, a dignity recognized from the natural law, as such, per man he has human rights are fundamental rights as are recognized in international instruments and regulated by the Constitutions to enforce the idea of the dignity of all people, the principles to which reference is made to freedom, dignity and equality.
\end{abstract}

\section{Sobre o autor}

Doutor em Direito Constitucional pela Universidad Autónoma de Aguascalientes. Advogado e mestre em direito constitucional pela Universidad de Guadalajara. Mestre em Direito Eleitoral pelo Instituto Prisciliano Sánchez. Docente dos programas de licenciatura, mestrado e doutorado da U. de G. Secretário do Estudio y Cuenta del Tribunal Electoral do Poder Judicial de la Federación.

1. Artigo traduzido por Camila Seraphim Makarausky. 
Human rights are closely related to fundamental rights, but are not synonymous, so it is necessary to define, which is achieved in this work. Civil and political rights, among others, the active voting, passive ballot free membership and association affairs politicians are human and fundamental rights enshrined in our Constitution and international instruments, so that the Mexican State must safeguard them and ensure their protection. However, also in the states of Mexico, including the State of Jalisco, there must be mechanisms constitutional and conventional control to protect fundamental human rights constituencies, hence the need to analyze whether the system of state constitutional justice effectively fulfill the obligation of protection.

Keywords: Fundamental rights; human; active vote; passive vote; protection; protection.

Artigo recebido em 17 de dezembro de 20।4; aceito para publicação em 4 de fevereiro de 2015.

\section{Conceituação dos direitos fundamentais e direitos humanos}

O tema dos direitos humanos foi estudado amplamente através da história da humanidade, pelo simples motivo de serem inerentes ao homem, sendo mais enfatizada sua análise em momentos históricos conjunturais nos quais sua garantia foi posta em perigo, como ocorreu durante as Guerras Mundiais, Golpes de Estado, ou outras situações que atentam contra a dignidade humana e contra o respeito destes direitos - os quais deverão sempre prevalecer frente a qualquer interesse social ou político.

O ser humano tem, por si só e de forma inata, uma dignidade reconhecida desde o direito natural, sendo-lhe reconhecido direitos humanos que "se refieren a aquellos principios que se ubican en la esfera jurídica del ser humano y que tienen que ser tutelados o respetados por las autoridades del Estado" (Quiroz 2002, 149).

É possível definir direitos humanos como “el conjunto de prerrogativas inherentes a la naturaleza de la persona, cuya realización efectiva resulta indispensable para el desarrollo integral del individuo que vive en una sociedad jurídicamente organizada" (Pedroza 2006, 253). Para o autor Juan Palomar de Miguel, são o "conjunto de libertades, prerrogativas y facultades, con sus correspondientes instrumentos de garantía, que deben reconocerse a 
todo ser humano, tanto en su aspecto individual como colectivo" (Palomar 2000, 468).

Para alguns autores, os direitos humanos guardam estreita relação com os direitos fundamentais. Carlos Bernal Pulido aduz que:

La idea principal es que los derechos fundamentales son una especie del género de los derechos subjetivos, que se definen por una característica específica: su fundamentalidad. La fundamentalidad, por su parte, consiste en un conjunto de propiedades formales y materiales [...] que tienen que ver con la protección de las propiedades básicas de una persona liberal, democrática y de aquella que es presupuesta por el Estado Social, tienen una primacía sobre las propiedades formales. Las propiedades formales, a su vez, se refieren a la inclusión de los derechos fundamentales en el texto constitucional, en el llamado bloque de constitucionalidad o en la jurisprudencia de los altos tribunales. En México, el reconocimiento de un derecho por parte del Tribunal Electoral del Poder Judicial de la Federación como un derecho fundamental, es una propiedad constitutiva del concepto de derecho fundamental. (Bernal 2009, 9-10).

Por sua vez, podemos definir os direitos fundamentais como o conjunto de atribuições reconhecidas pelos instrumentos internacionais e reguladas pelas Constituições, afim tornar efetiva a ideia da dignidade de todas as pessoas e, por consequência, permitir uma existência minimamente digna desde os âmbitos mais diversos - como o individual, o social, o político, o econômico e o cultural. Tais direitos se encontram dentro do rol dos direitos fundamentais estabelecidos pela Carta Magna, protegendo-se assim os direitos humanos.

Os direitos humanos podem ser divididos em três grandes grupos ou tipos: a) direitos civis e políticos (direitos humanos de primeira geração); b) direitos econômicos, sociais e culturais (direitos de segunda geração); e c) direitos dos povos ou da solidariedade. Trata-se de direitos que se encontram geralmente reconhecidos pelas constituições de muitos países - estando entre elas a norma constitucional mexicana -, bem como nos instrumentos internacionais em relacionados aos direitos humanos.

Definem-se como direitos políticos, levando em consideração o regulado pelo artigo XX, da Declaração Americana dos Direitos e 
Deveres do Homem ${ }^{2}$, como aqueles direitos que possui toda pessoa legalmente capacitada para participar do governo de seu país, diretamente ou por meio de seus representantes, e de participar nas eleições populares, por meio do voto secreto, universal e igual, sendo autênticas, periódicas e livres.

Os direitos políticos são direitos humanos e fundamentais que, além de estarem regulados e reconhecidos nos instrumentos anteriormente mencionados, "pueden ser reconocidos como garantías constitucionales estatales" (González 2007, 102), atendendo assim ao que ordena o artigo $1^{\circ}$ da Constituição Política dos Estados Unidos Mexicanos, no sentido de que todas as pessoas gozarão dos direitos humanos reconhecidos pela própria Constituição e pelos tratados internacionais dos quais o Estado Mexicano faça parte, assim como das garantias para sua proteção, cujo exercício não poderá restringir-se nem suspender-se, salvo nos casos em que a mesma Norma estabelecer.

Nesta conjuntura, os direitos civis e políticos que detém os cidadãos podem enquadrar-se em três categorias (González 2007, 102-6):

Direito de petição, iniciativa de lei, referendo e plebiscito;

Equidade de gênero, tanto para ocupar cargos públicos como para atuar como candidatos dos partidos políticos;

Direitos políticos específicos [...] direito de petição em matéria política, direito a exigir dos servidores públicos eleitos o cumprimento de suas promessas de campanha, direito a fomentar e exercer os instrumentos de participação cidadã que estabeleça a lei, direito a voto, direito a ocupar os cargos eleitorais que que lhe é atribuído, direito a ser votado, direito de associação e de livre afiliação política.

Nos instrumentos internacionais em matéria de direitos humanos, como o são a Declaração Universal de Direitos Humanos, o Pacto Internacional de Direitos Civis e Políticos, Declaração Americana dos Direitos e Deveres do Homem e a Convenção Americana sobre Direitos Humanos, infere-se um catálogo de direitos civis e políticos - vinculados, por suposto, ao direito eleitoral - como o direito

2. A citada Declaração Americana dos Direitos e Deveres do Homem, aprovada na IX Conferência Internacional Americana em 1948, em Bogotá, Colômbia, encontra-se disponível na internet, na página oficial da Organização dos Estados Americanos: http://www.oas.org/es/cidh/mandato/Basicos/declaracion.asp, data de consulta: 06 de setembro de 2013. 
à igualdade e o direito à liberdade, direitos políticos, democráticos e administrativos, bem como direitos de administração e acesso à justiça.

Do citado catálogo de direitos, "el derecho internacional de los derechos humanos establece las obligaciones que tienen los gobiernos de tomar medidas en determinadas situaciones o de abstenerse de actuar de determinada forma en otras, a fin de proteger los derechos humanos y las libertades fundamentales de los individuos o grupos" (Miranda y Díaz 2013, 430), pelo que se pode concluir que os direitos políticos são direitos humanos reconhecidos pela Carta Magna - portanto, direitos fundamentais, restando obrigados à sua tutela e proteção os estados que tenham aderido aos instrumentos internacionais que o regulam. Assim, pode-se dizer que "es necesario que el estado democrático mexicano garantice su protección y salvaguarda" (Miranda y Díaz 2013, 432).

Neste contexto, o México aderiu a instrumentos e tratados, como a Declaração Universal de Direitos Humanos, o Pacto Internacional de Direitos Civis e Políticos, que foi adotado pela Assembleia Geral da Organização das Nações Unidas em 16 de dezembro de 1966, na cidade de Nova Iorque, a qual o México também aderiu, como foi publicado no Diário Oficial da Federação em 20 de maio de 1981, entrando em vigor dia 23 de julho do mesmo ano; a Convenção Americana sobre Direitos Humanos (Pacto de São José) firmado em São José, Costa Riva, em 22 de novembro de 1969, à qual o México aderiu em 23 de março de 1981, publicando-se tal adesão no Diário Oficial da Federação em 07 de maio do mesmo ano; e a Convenção sobre os Direitos Políticos da Mulher, cuja adesão deste país se publicou no Diário Oficial da Federação em 28 de abril de 1981, entrando em vigor em 21 de junho deste mesmo ano.

Afim de proteger os direitos humanos, a raiz da reforma ocorrida em 10 de junho de 2011, em seu artigo $1^{\circ}$, parágrafo $3^{\circ}$, da Carta Magna, determina que todas as autoridades, no âmbito de sua competência, têm a obrigação de promover, respeitar, proteger e garantir os direitos humanos em conformidade aos princípios da universalidade, interdependência, indivisibilidade e progressividade. Consequentemente, o Estado deverá prevenir, investigar, sancionar e reparar as violações aos direitos humanos, nos termos estabelecidos pela legislação. 


\section{Regulação dos direitos fundamentais eleitorais e sua tutela pela Carta Magna}

Em continuidade, o respeito ao estado de direito que deve imperar em nosso país - e em cada uma das entidades federativas - encontrase delineado pela norma constitucional e se evidencia na aplicação de seus princípios e postulados; a Constituição Política dos Estados Unidos Mexicanos não deve ser compreendida como "letra morta", pelo contrário, deve ser vigente, e os princípios que postula objeto de estrita observância.

Assim prescreve:

Artículo 1o. En los Estados Unidos Mexicanos todas las personas gozarán de los derechos humanos reconocidos en esta Constitución y en los tratados internacionales de los que el Estado Mexicano sea parte, así como de las garantías para su protección, cuyo ejercicio no podrá restringirse ni suspenderse, salvo en los casos y bajo las condiciones que esta Constitución establece. Las normas relativas a los derechos humanos se interpretarán de conformidad con esta Constitución y con los tratados internacionales de la materia favoreciendo en todo tiempo a las personas la protección más amplia. Todas las autoridades, en el ámbito de sus competencias, tienen la obligación de promover, respetar, proteger y garantizar los derechos humanos de conformidad con los principios de universalidad, interdependencia, indivisibilidad y progresividad. En consecuencia, el Estado deberá prevenir, investigar, sancionar y reparar las violaciones a los derechos humanos, en los términos que establezca la ley. [...] (CPEUM, artículo $1^{\circ}$, párrafos primero, segundo y tercero).

Da leitura do artigo anterior, observa-se que o legislador intitulou o Título Primeiro, Capítulo I, como "Dos Direitos Humanos e suas Garantias" e através dele outorgou certa hierarquia ou prevalência a valores de caráter ético que devem reger e servir de parâmetro para a interpretação das normas do ordenamento jurídico, às quais devem observar todas as autoridades, tanto administrativas quanto jurídicas. Tal o é que, no caso das administrativas, o artigo 102, Base $\mathrm{B}$, da própria Constituição Política, estabelece que tanto o Legislativo Federal, como as legislaturas estatais, em sua competência, estabelecerão organismos de proteção dos direitos humanos que ampara 
o ordenamento jurídico mexicano, os quais conhecerão das queixas contra os atos ou omissões de natureza administrativa provenientes de qualquer autoridade ou servidor público - com exceção do Poder Judiciária da Federação - que violem estes direitos.

Nesta seara, os direitos fundamentais eleitorais que a Carta Magna estabelece em seus artigos $1^{\circ}, 2^{\circ}, 3^{\circ}, 4^{\circ}, 6^{\circ}, 7^{\circ}, 8^{\circ}, 9^{\circ}, 30,34$, $35,36,41,60,99,116$ e 122 assim se traduzem:

a. Os direitos dos povos indígenas à livre determinação e autonomia para eleger de acordo com suas normas, procedimentos e práticas tradicionais as autoridades ou representantes para o exercício de suas formas próprias de governo interno, garantindo a participação das mulheres em condições de equidade frente aos homens, em um quadro que respeite o pacto federal e a soberania dos estados;

b. O direito à educação democrática;

c. Os direitos de igualdade, em que o homem e a mulher são iguais perante a lei, incluindo em matéria de exercício de direitos civis, políticos e eleitorais;

d. Os direitos de liberdade de expressão (sempre e quando não se ataque a moral, a vida privada ou os direitos de terceiros, ou provoquem algum delito, perturbando a ordem pública) -, de réplica e de acesso à informação;

e. Os direitos de liberdade de difusão de informação, opiniões e ideias em cumprimento ao exercício da liberdade de expressão;

f. O direito de petição (que deverá ser por escrito de forma pacífica e respeitosa);

g. O direito de livre associação ou reunião pacífica com qualquer objeto lícito, de reserva para os cidadãos mexicanos quando se trata de tomar parte de assuntos políticos do país;

h. Os direitos inerentes ou derivados da nacionalidade mexicana;

i. O direito ao voto ativo para as eleições e consultas populares sobre temas de transcendência nacional (direito derivado da qualidade de cidadão);

j. Direito ao voto passivo para ocupar os cargos de eleição popular, tanto postulados pelos partidos políticos, como de forma independente (direito derivado da qualidade de cidadão);

k. Direito à associação livre e individual para tomar parte nos assuntos políticos do país (direito derivado da qualidade de cidadão); 
1. Direito a ter eleições livres, autênticas e periódicas, para renovação dos poderes Legislativo e Executivo, no caso das entidades federativas e dos prefeituras nos municípios, e renovação do Chefe de Governo e da Assembleia Legislativa no Distrito Federal;

m. Direito a que se respeite o sufrágio universal, livre, secreto e direto;

n. Direito a constituir e afiliar-se a partidos políticos e agrupamentos políticos;

o. Direito a contar com autoridades eleitorais administrativas, tanto federal nas entidades federativas, como no Distrito Federal, que governam baixo os princípios reitores da função eleitoral, tais como a certeza, legalidade, independência, imparcialidade e objetividade; e

p. Direito a contar com autoridades eleitorais jurisdicionais, tanto federal nas entidades federativas e no Distrito Federal, que exerça um sistema de meios de impugnação em matéria eleitoral, baixo o respeito aos princípios da constitucionalidade, legalidade, celeridade e prontidão na resolução de conflitos eleitorais, assim como a conclusão definitiva das etapas dos processos eleitorais, garantia de audiência e defesa, a irretroatividade e devida fundamentação e motivação de suas resoluções e sentenças. Tudo isso com a finalidade de garantir que todos os atos e resoluções das autoridades eleitorais, inclusive de partido político em caso de direitos político-eleitorais, se atenham ao princípio da legalidade.

Do acima exposto, observa-se que a Constituição Política dos Estados Unidos Mexicanos regula um rol de direitos que se denominarão fundamentais eleitorais, que nas palavras de Luis Rolando Escalante Topete, trata-se "de todos aquellos derivados de la participación de todo individuo en las actividades vinculadas con el Estado en el ejercicio de la función pública [...] con la limitante de que sólo podrán hacer uso de estos derechos los ciudadanos mexicanos" (Escalante, 367).

Portanto, para o respeito dos direitos citados - de base constitucional -, o Estado deve contar com uma tutela judicial efetiva e ordinária, com um controle constitucional, entendendo-se que "los medios de control constitucional son instrumentos que prevé el propio orden normativo y la Constitución, por supuesto, para la defensa de la supremacía y vigencia del orden constitucional" (Benítez, 2005,94), ainda mais que se trata de um "controle constitucional difuso", como se refere o autor Raúl Montoya Zamora, ao assinalar que "todos los 
jueces y órganos encargados de la impartición de justicia, o sea, los que realicen funciones materialmente jurisdiccionales, se encuentran facultados para ejercitar el denominado "control difuso" (Montoya 2013, 101), quem também nos explica que:

la Suprema Corte de Justicia de la Nación, reconoció la existencia de dos grandes vertientes dentro del modelo de control de constitucionalidad en México que son acordes con un modelo de control de convencionalidad. En primer orden, el control concentrado a cargo de los órganos del Poder Judicial de la Federación con mecanismos directos de control [...] En segundo término, el control difuso, que le compete al resto de los jueces del país, en forma incidental durante los procesos ordinarios en los que son competentes [...] (Montoya, 2013, 101-2)

Ante o exposto, no caso do México, se tratamos exclusivamente sobre direitos fundamentais eleitorais, como sabemos, tem-se um tribunal eleitoral no âmbito federal ${ }^{3}$ que possui, dentre suas competências, resolver os Juízos de Revisão Constitucional Eleitoral e Juízo para a Proteção dos Direitos Político-Eleitorais do Cidadão, reservando as ações de inconstitucionalidade e controvérsias constitucionais à Suprema Corte de Justiça da Nação. Também há nas entidades federativas tribunais e salas eleitorais locais no âmbito de sua jurisdição - se bem que não é uniforme quanto aos meios de impugnação adotados -, podendo exercer dentro de sua competência um controle de constitucionalidade e legalidade nesta matéria, sendo garantidores dos direitos políticos e eleitorais, assim como dos diversos princípios constitucionais relacionados.

Nestes não apenas se exerce um controle de constitucionalidade, mas trata-se também do chamado "controle de convencionalidade", o qual se entende, conforme palavras de Ignacio Francisco Herrerías Cuevas:

3. Dentro da competência do Tribunal Eleitoral do Poder Judiciário da Federação, enfatiza-se que, em virtude do Decreto de 13 de novembro de 2007, pelo qual se reformaram os artigos $6^{\circ}, 41,85,99,108,116$ y 122 , se adicionou o artigo 134 e se derrogou um parágrafo do artigo 97 da Constituição Política dos Estados Unidos Mexicanos (disponível na internet: http://www.funciónpública.gob.mx/ unaopspf/doctos/adquisiciones/dof131107.pdf) é que outorgou-se ao citado órgão jurisdicional a faculdade para declarar a inaplicação de leis eleitorais contrárias à Constituição, com efeitos particulares ao caso concreto, o que resulta em deixar sem efeito qualquer critério da Suprema Corte de Justiça que tenha emitido sobre o particular. 
“[...] un sistema para la salvaguarda de los derechos fundamentales de todo individuo reconocidos en los tratados internacionales, obligando a los tribunales nacionales a dotar de contenido las normas que rigen su actuar, lo que paulatinamente se ha denominado 'Control de Convencionalidad". (Herrerías 2011, 21).

O controle de convencionalidade encontra fundamento no dispositivo constitucional que assim estabelece:

Artículo 133. Esta Constitución, las leyes del Congreso de la Unión que emanen de ella y todos los Tratados que estén de acuerdo con la misma, celebrados y que se celebren por el Presidente de la República, con aprobación del Senado, serán la Ley Suprema de toda la Unión. Los jueces de cada Estado se arreglarán a dicha Constitución, leyes y tratados, a pesar de las disposiciones en contrario que pueda haber en las Constituciones o leyes de los Estados (CPEUM, artículo 133).

Assim, a materialização do controle de constitucionalidade e convencionalidade se dá na medida em que se aplicam as obrigações dos estados membros dos instrumentos internacionais dos que formem parte, como é o caso do México, que aderiu a tratados desta natureza como já citado em parágrafos anteriores.

Os controles citados, em matéria eleitoral, conforme leciona Raúl Montoya Zamora, podem ser denominados como "control de constitucionalidad-convencionalidad difuso" (Montoya 2013,104), cuja competência se estende também a alguns órgãos do Instituto Federal Eleitoral e órgãos das autoridades administrativas eleitorais, detentores de funções materialmente jurisdicionais.

Quanto ao Tribunal Eleitoral do Poder Judicial da Federação, suas salas eleitorais regionais possuem a faculdade de afastar uma norma eleitoral quando esta for contrária à Carta Magna ou a um tratado internacional em matéria de direito humano do qual o México tenha aderido, caso no qual deverá informar a Suprema Corte de Justiça da Nação.

Estas salas eleitorais devem adotar uma interpretação coerente, devendo expor suas razões e porque entende que a norma está de acordo com a constitucionalidade e convencionalidade, buscando a todo momento a interpretação que conceda a proteção mais ampla às pessoas. 
O controle difuso de constitucionalidade e convencionalidade que deve realizar o Tribunal Eleitoral do Poder Judiciário da Federação ao conhecer uma controvérsia é exercido ex officio, invocando ou não as partes, pois se aplicassem uma norma contrária à constitucionalidade e convencionalidade permitiriam certa vulnerabilidade a direito humano de alguma das partes, violando conjuntamente a Convenção Americana sobre Direitos Humanos.

Esta aplicação do controle de constitucionalidade e convencionalidade deve se estender a todos os juízes eleitorais nos tribunais e zonas eleitorais, que exercerão este controle sobre todos os casos concretos que estejam sob sua competência, conduzindo uma interpretação coerente e harmonizada com a constitucionalidade e convencionalidade e, se necessário for, afastar a aplicação da norma para o caso concreto analisado.

Diante do acima exposto, para uma melhor aproximação e abordagem - que não poucos juristas e estudiosos têm feito - afim de favorecer os direitos fundamentais e harmonizar o respeito ao princípio da "supremacia constitucional”, não seria conveniente que, no México, se instaurasse um Tribunal Constitucional propriamente dito, como um garantidor superior e definitivo da constitucionalidade e proteção destes direitos?

Neste sentido, este seria um caminho viável, ou ainda, uma tendência internacional - basta ver a experiência traçada em outros países latino-americanos e europeus, onde tal órgão protecionista constitucional já existe, como é o caso da Bolívia, Colômbia, Guatemala, Peru e, no caso europeu, Áustria, Alemanha, Espanha e Itália, entre tantos mais. Em tais casos, verificam-se resultados positivos em resolver conflitos de violação dos direitos humanos vinculados, por exemplo, à liberdade e à igualdade, os quais se encontram reconhecidos e regulados em suas respectivas normas fundamentais, possibilitando, inclusive, um controle prévio de constitucionalidade dos tratados internacionais (como ocorre no caso espanhol).

Nas entidades federativas também existe uma supremacia e defesa das constituições locais, defesa esta que

“[...] debe darse por los tribunales de las entidades federativas; que surge frente a la necesidad de establecer instituciones jurídicas que garanticen la supremacía de las Constituciones para así mantener 
un Estado de derecho, garantizando los objetivos del federalismo y la democracia de México” (González Alcántara 2006, 893).

Nesse sentido, como bem resumido por Edudardo Ferrer MacGregor $^{4}$, nas seguintes entidades federativas se conta com mecanismos de controle concreto de constitucionalidade: Campeche, Chiapas, Chihuahua, Coahuila, Colima, Durango, Estado de México, Guanajuato, Guerrero, Hidalgo, Morelos, Nuevo León, Oaxaca, Querétaro, Quintana Roo, Sinaloa, Tabasco, Tlaxcala, Veracruz y Zacatecas (lista a qual se soma o Estado de Jalisco, em cuja Constituição, artigo 70, fração IV, se prevê como competência do Tribunal Eleitoral a resolução de impugnações de atos e resoluções que violem os direitos políticos eleitorais dos cidadãos), nos quais são diversificados os mecanismos previstos, baseados em amparo legal, ações de inconstitucionalidade, controvérsias constitucionais sobre questões de inconstitucionalidade e ação por omissão legislativa.

Das entidades listadas que contam com um mecanismo de controle de constitucionalidade, em sua grande maioria a competência para conhecer destes conflitos, bem como resolve-los, é do tribunal superior de justiça. Nos demais, como é o caso de Chiapas (onde se denomina o tribunal constitucional como Tribunal Superior de Justiça do Estado), Estado do México, Quintana Roo e Veracruz, a competência recai a uma chamada Sala Constitucional - no caso de Veracruz, por exemplo, trata-se de uma Sala pertencente ao Tribunal Superior de Justiça deste Estado.

Entende-se eu em nada afeta o federalismo mexicano o fato de que em todas as entidades federativas se conta com mecanismos de controle constitucional, o qual resta fortalecido, já que assim “los estados en ejercicio de su autonomía, deben formular los medios jurídicos necesarios para la defensa de su norma fundamental, base del orden jurídico local" (González Alcántara 2006, 895).

Em continuidade, a este presente trabalho interessa também elucidar quais das entidades-membro do Pacto Federal contam com os meios ou mecanismos para a tutela dos direitos fundamentais

4. Síntese da exposição feita na Primeira e Segunda mesas sobre La justicia constitucional en las entidades federativas, efetuadas nas cidades de Oaxaca (12 e 13 de novembro de 2004) e Tlaxcala (6 a 8 de outubro de 2005). 
de caráter eleitoral, ou seja, dos direitos políticos e eleitorais regulados em suas respectivas constituições. Atualmente verificam-se tais mecanismos nos seguintes estados: Chiapas, Coahuila, Colima, Distrito Federal, Durango, Guanajuato, Guerrero, Jalisco, Morelos, Nayarit, Oaxaca, Puebla, Quintana Roo, Tabasco, Tamaulipas, Tlaxcala, Veracruz, Yucatán e Zacatecas, nos quais se encontra regulado um juízo que protege estes direitos, cuja denominação é variável, como "juízo para a proteção dos direitos político-eleitorais do cidadão", "juízo para a defesa cidadã eleitoral”, "juízo eleitoral cidadão" " "recurso de defesa dos direitos político-eleitorais", entre outros similares. Isto significa que apenas pouco mais da metade dos estados da República Mexicana os contemplam.

Como sabemos, ao não constituir claramente este juízo de garantias para a tutela e proteção dos direitos político-eleitorais - os quais são direitos humanos fundamentais -excluem taxativamente no artigo 61, da Lei de Amparo5, que, em matéria eleitoral, regula especificamente o meio de impugnação idôneo para a defesa destes direitos, que a nível federal se denomina juízo para a proteção dos direitos político-eleitorais do cidadão, e como vimos, guarda similar denominação nas constituições e legislações secundárias que também o estabelecem.

O citado meio de impugnação eleitoral pode ser definido, nas palavras do autor Flavio Galván Rivera, como:

5. O citado preceito da Lei de Amparo assim dispõe: "Artículo 61. El juicio de amparo es improcedente: I a XIV [...] XV. Contra las resoluciones o declaraciones de las autoridades competentes en materia electoral; XVI a XXIII [...]". A respeito, cabe recordar a chamada tese da incompetência de origem (todo oficial que é nomeado contra o disposto pela Constituição e pelas leis que dela emanem, na qual a Suprema Corte possuía competência para resolver juízos de amparo sobre controvérsias de caráter ou vinculação eleitoral), a qual sustentou e defendeu José María Iglesias, em 1857, e que posteriormente chegaria à postura antiética de então Ministro Presidente da Suprema Corte de Justiça da Nação, Ignacio Luis Vallarta, quem propôs que deveriam diferenciar as soluções sobre questões políticas das controvérsias de índole judicial, base ideológica de Vallarta que finalmente levou a manter uma nova tese no sentido de que "la cuestión de legitimidad es meramente política y no corresponde a la justicia federal resolverla en juicios de amparo", que sustentou Vallarta, citado pelo Professor Flavio Galván Rivera em sua obra Derecho Procesal Electoral Mexicano, 2006. México: Porrúa, p. 225. 
[...] la vía legalmente establecida, a favor exclusivo de los ciudadanos para impugnar procesalmente la constitucionalidad, legalidad y validez de un acto o resolución electoral, que viole el derecho ciudadano de votar o ser votado en elecciones populares, de asociación individual y libre para participar pacíficamente en asuntos políticos del país o de afiliación libre e individual a los partidos políticos. (Galván, 2006, 692).

Trata-se, assim, de uma via legal ordinária e específica para que os cidadãos possam defender judicialmente, se necessário, seus direitos político-eleitorais fundamentais quando considerem que estes foram violados, afim de garantir o respeito a estas prerrogativas, situação própria de um estado democrático, como dispões a Carta Magna em seu artigo 40.

\section{Os direitos fundamentais e sua tutela na normativa eleitoral local: o diagnóstico do caso Jalisco}

Paralelamente à regulamentação dos direitos fundamentais eleitorais pela Carta Magna, em seu Título Primeiro, Capítulo III, intitulado "Dos direitos humanos e suas Garantias”, a Constituição Política do Estado de Jalisco, particularmente em seu artigo $4^{\circ}$, prevê a obrigação de toda autoridade de salvaguardar os direitos de que goza toda pessoa, afim de proteger e garantir o direito à vida.

Respeito aos direitos humanos reconhecidos, o artigo mencionado acima assim os lista:

q. Os enunciados da Constituição Federal;

r. Os conteúdos da Declaração Universal dos Direitos Humanos, proclamada pela Assembleia Geral das Nações Unidas, na Convenção Americana de Direitos Humanos; e

s. Os conteúdos dos tratados, convenções e acordos internacionais que o Governo Federal tenha firmado ou faça parte.

Daí que, quanto aos direitos assinalados no capítulo que antecede o presente trabalho, aplicados à jurisdição desta entidade federativa sob o imperativo constitucional, podemos afirmar que as autoridades eleitorais - administrativas e jurídicas locais - estão obrigadas a proteger e tutelar, em benefício do cidadão jalisciense, o direito ao voto ativo, ao voto passivo, à livre e individual afiliação a partido político de sua preferência e de associação pacífica para fazer parte dos assuntos políticos do país e do Estado de Jalisco, o 
direito de petição, de liberdade de expressão e de acesso à informação, assim como outros direitos coletivos, como é o caso da livre determinação das populações e comunidades indígenas e grupos éticos na entidade.

A proteção e tutela destes direitos necessariamente requerem o apoio de mecanismos e instrumentos idôneos que garantem a sua aplicação e respeito, tanto pelas autoridades administrativas, quanto pelas jurisdicionais, estabelecendo a análise das controvérsias que a respeito lhes sejam atribuídas o princípio pro bomine, o qual não pode acontecer se não se conta com um meio de defesa ordinário, isto é, com um meio de impugnação específico para a resolução dos conflitos onde se resolvam supostas violações a direitos fundamentais eleitorais.

No caso do Estado de Jalisco, contempla-se como uma atribuição do Tribunal Eleitoral Local conhecer e resolver de forma definitiva e inatacável "las impugnaciones de actos y resoluciones que violen los derechos político-electorales de los ciudadanos a votar, a ser votado y a la afiliación libre y pacífica para tomar parte en los asuntos políticos del Estado" (CPEJ, artículo 70, fracción IV); contudo, por omissão legislativa, atualmente não se encontra regulado o meio de impugnação respectivo, nem na Lei Orgânica do Tribunal Eleitoral, nem no Código Eleitoral e de Participação Cidadã, ambas legislação deste Estado.

Diante da citada omissão, a primeira das controvérsias estabelecidas sobre assuntos desta natureza foi resolvida a partir de uma determinação adotada pela Sala Superior do Tribunal Eleitoral do Poder Judiciário da Federação, na sentença proferida nos autos de número SUP-JDC-12640/2011, pelo Juízo para a Proteção dos Direitos Político-Eleitorais do Cidadão, em 30 de novembro de 2011, em que se redirecionou o juízo acerca do meio de impugnação previsto no artigo 70, fração IV, da Constituição Política do Estado de Jalisco, para que o Tribunal Eleitoral desta entidade federativa o resolvesse em plenitude de jurisdição, instaurando, por consequência, um simples procedimento, respeitando as formalidades essenciais e baseada no emprego analógico das regras gerais dos meios de impugnação contidas no Título Segundo, Livro Sete, do Código Eleitoral local vigente, ou, quando necessário, nos princípios gerais do Direito Processual. 
No dia 08 de dezembro de 2011, o Pleno do Tribunal Eleitoral emitiu o acordo que permitiu definir o nome, a sigla e o procedimento para a comprovação e resolução do meio de impugnação, que se denominou Juízo para a Proteção dos Direitos Político-Eleitorais do Cidadão, registrado com o número de expediente JDC-001/20116. A primeira sentença deste juízo foi proferida em 05 de maio de 2012, da qual, para se fazer efetiva a tutela judicial, o órgão responsável levou em conta as normas relativas aos direitos humanos assim com sua interpretação em conformidade com a Constituição Federal e com os tratados internacionais acerca desta matéria, concedendo ampla proteção a todas as pessoas.

Assim, foi a partir do ano de 2011 que em Jalisco se estabeleceu efetivamente um juízo especializado para conhecer e resolver controvérsias relativas aos direitos fundamentais eleitorais, sem que por ele se tenha sanado ou retificado a omissão legislativa estadual com o efeito de regular ou regulamentar o Juízo para a Proteção dos Direitos Político-Eleitorais do Cidadão, omissão que ainda subsiste, apesar de que no tribunal eleitoral local se tenha resolvido um total de 358 processos, o que demonstra que esta entidade ainda não possui plena consciência da importância de contar com um meio de controle constitucional - até mesmo um controle difuso de convencionalidade - em benefício da cidadania e da prestação da justiça eleitoral.

\section{Conclusões}

Os direitos político-eleitorais são direitos humanos fundamentais, regulados e reconhecidos pelos instrumentos internacionais e garantidos constitucionalmente, cuja tutela e proteção se encontra sujeita à aplicação e exercício do controle difuso de constitucionalidade e convencionalidade por parte das autoridades eleitorais no México, particularmente, do Tribunal Eleitoral do Poder Judiciário da Federação e dos tribunais e salas eleitorais das entidades federativas, que se encontram obrigadas, nos limites de sua competência, a considerar as normas que tratem de direitos humanos, devendo sua

6. A sentença do Juízo para a Proteção dos Direitos Político-Eleitorais do Cidadão que se cita, encontra-se disponível na internet, na página oficial do Tribunal Eleitoral do Poder Judiciário do Estado de Jalisco: http://www.triejal.gob.mx/ jdc-001-2011/, fecha de consulta: 29 de enero de 2015. 
interpretação estar em conformidade com a Constituição Federal e com os tratados internacionais.

Não obstante, não há nas normas constitucionais das entidades federativas homogeneidade quanto aos meios de controle constitucional para a defesa dos direitos fundamentais, havendo apenas em alguns estados uma Sala Constitucional propriamente dita, pelo que se considera que um exercício que favoreceria a instauração completa da justiça constitucional eleitoral nos estados membros do pacto federal seria que em todos estes se criasse um tribunal constitucional eleitoral, ou uma sala constitucional eleitoral que tivesse competência exclusiva para conhecer e resolver controvérsias que relacionem direitos fundamentais eleitorais.

Especificamente quanto ao caso do Estado de Jalisco, pode-se observar que, devido a uma omissão legislativa, apesar da existência de previsão constitucional estabelecendo a faculdade do Tribuna Eleitoral e Jalisco para conhecer e resolver controvérsias sobre violação de direitos político-eleitorais do cidadão, na legislação adjetiva eleitoral local vigente não se encontra regulado um meio de impugnação para tanto, o que implicar um atraso legislativo na prestação da justiça eleitoral estadual, ainda mais se levamos em consideração que foi apenas a partir de novembro de 2011 que começaram a resolver assuntos desta natureza - os casos resolvidos o foram sem o apoio de uma regulamentação específica, como deveria haver em interesse à defesa e tutela efetiva destes direitos.

Ante o exposto, surge a proposta de reformar, a princípio, a Lei Orgânica do Tribunal Eleitoral, assim como adicionar um título ao Livro 7 (Sistema de Meios de Impugnação) do atual Código Eleitoral e de Participação Cidadã, ambos ordenamentos do Estado de Jalisco, que se intitula Juízo para a Proteção dos Direitos Político-Eleitorais do Cidadão, no qual se inclui procedimento e regras específicas para a tramitação, condução e resolução do processo, solucionando o atual vazio legal.

\section{Bibliografia}


Benítez Treviño, Humberto. (2005). La Sala Constitucional del Estado de México como expresión del federalismo del siglo XXI. México: Instituto de Investigaciones Jurídicas, UNAM.

Bernal Pulido, Carlos. (2009). Los derechos fundamentales en la jurisprudencia del TEPJF. Temas selectos del Derecho Electoral Núm 8. México: Tribunal Electoral del Poder Judicial de la Federación.

Escalante Topete, Luis Rolando. (2013) Los Derechos Político-Electorales del Ciudadano habitante y residente en Baja California, disponible en internet: http:// biblio.juridicas.unam.mx/libros/4/1784/22.pdf, fecha de consulta 13 de septiembre de 2013.

Galván Rivera, Flavio. (2006). Derecho Procesal Electoral Mexicano. México: Porrúa.

González Alcántara, Juan Luis. Perspectivas de las Entidades Federativas sin control constitucional. En La Justicia Constitucional en las Entidades Federativas, coords. Manuel González Oropeza y Eduardo Ferrer Mac-Gregor, 887-904. México: Porrúa.

González Oropeza, Manuel. (2007). Los derechos políticos y su protección en las constitucionales de las entidades federativas de México. Trabajo presentado en "Memorias de la cuarta mesa redonda sobre Justicia Constitucional en las Entidades Federativas”, coord. Manuel González Ororpeza, 14 al 16 de noviembre de 2007, en Chiapas, México: SCJN y TEPJF

Herrerías Cuevas, Ignacio Francisco. (2011). Control de convencionalidad y efectos de las sentencias. México: Editorial Ubijus.

Miranda Camarena, Adrián Joaquín y Díaz Cortés, Ma. del Carmen. (2013). El control de la convencionalidad en la tutela de los derechos político-electorales de los ciudadanos en México. En Justicia Constitucional Local, coords. Luis Antonio Corona Nakamura, José Pablo Martínez Gil y Adrián Joaquín Miranda Camarena, 428-59. México: Instituto Prisciliano Sánchez y UNAM.

Montoya Zamora, Raúl. (2013). “Características del control de constitucionalidad y convencionalidad realizado por los jueces en materia electoral".Quid Iuris. Año 7, Volumen 21 (junio-agosto): 99-114.

Palomar De Miguel, Juan. (2000). Diccionario para Juristas. Tomo I, A-I. México: Porrúa.

Pedroza de la Llave, Susana Thalía. (2006). Los derechos humanos y políticos de las mujeres. En Estudios en homenaje a Marcia Muñoz de Alba Medrano. Protección de la persona y derechos fundamentales, coords. David Cienfuegos Salgado y María Carmen Macías Vázquez, 253-72. México: Instituto de Investigaciones Jurídicas, Serie Doctrina Jurídica, Núm. 324, UNAM.

Quiroz Acosta, Enrique. (2002). Lecciones de Derecho Constitucional. México: Porrúa. Sites da Internet:

SCJN. Suprema Corte de Justicia de la Nación. 
http://www2.scjn.gob.mx/red/constitucion

Tribunal Constitucional de Bolivia

www.tribunalconstitucional.cl

Corte Constitucional de Colombia

http://www.corteconstitucional.gov.co/lacorte/

Corte de Constitucionalidad de Guatemala

http://www.cc.gob.gt/

Corte Constitucional de Austria

http://www.vfgh.gv.at/cms/vfgh-site/english/index.html

Corte Constitucional de Italia

http://www.cortecostituzionale.it/default.do

Tribunal Constitucional de Alemania

http://www.bundesverfassungsgericht.de/

Tribunal Constitucional de España

http://www.tribunalconstitucional.es/es/Paginas/Home.aspx

Tribunal Constitucional de Perú

http://www.tc.gob.pe/

Poder Judicial del Estado de Veracruz

www.pjeveracruz.gob.mx

Organización de Estados Americanos

http://www.oas.org/es/cidh/mandato/Basicos/declaracion.asp

TEJEJ. Tribunal Electoral del Estado de Jalisco

http://www.triejal.gob.mx/jdc-001-2011/, fecha de consulta: 29 de enero de 2015.

\section{Legislações:}

CPEUM. Constitución Política de los Estados Unidos Mexicanos, disponible en internet en el sitio: http://www.diputados.gob.mx/LeyesBiblio/pdf/1.pdf, consultada el 10 de septiembre de 2013.

http://www.funciónpública.gob.mx/unaopspf/doctos/adquisiciones/dof131107.pdf consultada el 10 de septiembre de 2013.

Ley de Amparo, disponible en internet en el sitio: http://www.diputados.gob.mx/ LeyesBiblio/pdf/LAmp.pdf, consultada el 17 de septiembre de 2013.

Constituciones Políticas de los Estados de Campeche, Chiapas, Chihuahua, Coahuila, Colima, Durango, México, Guanajuato, Guerrero, Hidalgo, Jalisco, Morelos, Nayarit, Nuevo León, Puebla, Oaxaca, Querétaro, Quintana Roo, Sinaloa, Tabasco, Tamaulipas, Tlaxcala, Veracruz, Yucatán y Zacatecas. 
